This item was submitted to Loughborough's Research Repository by the author.

Items in Figshare are protected by copyright, with all rights reserved, unless otherwise indicated.

\title{
The effects of solar radiation on thermal comfort
}

\section{PLEASE CITE THE PUBLISHED VERSION}

https://doi.org/10.1007/s00484-006-0050-y

\section{PUBLISHER}

Springer Science and Business Media LLC

\section{VERSION}

AM (Accepted Manuscript)

\section{PUBLISHER STATEMENT}

This paper was accepted for publication in the journal International Journal of Biometeorology and the definitive published version is available at https://doi.org/10.1007/s00484-006-0050-y

\section{LICENCE}

CC BY-NC-ND 4.0

\section{REPOSITORY RECORD}

Hodder, Simon, and Ken Parsons. 2006. "The Effects of Solar Radiation on Thermal Comfort". Loughborough University. https://hdl.handle.net/2134/15164034.v1. 


\section{The effects of solar radiation on thermal comfort}

*Simon G Hodder, and `Ken Parsons,

${ }^{*}$ Department of Design and Technology and ${ }^{+}$Department of Human Sciences

Loughborough University

Loughborough

Leicestershire

LE11 3TU, UK

${ }^{+}$Corresponding author

Telephone: $+44(0) 1509223023$

Fax: $+44(0) 1509223940$

S.Hodder@lboro.ac.uk, K.C.Parsons@lboro.ac.uk

\section{Abstract}

The aim of this study was to investigate the relationship between simulated solar radiation and thermal comfort. Three studies investigated the effects of: 1 , the intensity of direct simulated solar radiation, 2 , spectral content of simulated solar radiation, and 3, glazing type; on human thermal sensation responses. Eight male subjects were exposed in each of the three studies. In Study 1, subjects were exposed to four levels of simulated solar radiation, 0 , 200, 400 and $600 \mathrm{Wm}^{-2}$. In Study 2, subjects were exposed to simulated solar radiation with four different spectral contents each with a total intensity of $400 \mathrm{Wm}^{-2}$ on the subject. In Study 3 subjects were exposed through glass to radiation caused by $1000 \mathrm{Wm}^{-2}$ of simulated solar radiation on the exterior surface of four different glazing types. The environment was otherwise thermally neutral where there was no direct radiation, PMV $=0 \pm 0.5$, (ISO 7730: 1994). Ratings of thermal sensation, comfort, stickiness and preference and measures of mean skin temperature were taken. Increase in the total intensity of simulated solar radiation rather than the specific wavelength of the radiation is the critical factor affecting thermal comfort. The thermal sensation votes showed that there was a sensation scale increase of 1 Page 1 of 36 
scale unit for each increase of direct radiation of around $200 \mathrm{Wm}^{-2}$. The specific spectral content of the radiation has no direct effect on thermal sensation. The results contribute to models for determining the effects of solar radiation on thermal comfort in vehicles, buildings and outdoors.

\section{Keywords}

Thermal sensation, solar radiation, spectral content, radiation intensity, glazing.

\section{Introduction}

Solar radiation has been shown to cause considerable discomfort to people in vehicles, Rohles and Wallis (1979), Madsen et al (1992), Parsons and Entwhistle (1983), Bohm et al (1997) and Parsons (2003). It can also be a source of dissatisfaction in buildings, when people are next to windows, and outdoors. Despite this, there have been no specific studies of the relationship between level and characteristics of solar radiation to which people are exposed and the discomfort it causes. The aim of this study was to determine that relationship.

\subsection{Solar radiation and thermoregulation}

The solar radiation that passes through the atmosphere can be divided into three regions, ultra violet (UV), Visible and infra red (IR), which are divided into sub sections. Only a small section of the spectrum is visible to the human eye. But this section contains $45 \%$ of the energy emitted as well as the peak levels of energy intensity, (Givoni 1976), with UV and IR radiation accounting for $5 \%$ and $50 \%$ respectively.

Studies that have investigated the effects of solar radiation on thermoregulation have used two main techniques; a) measurement from physiological responses and b) responses of thermal manikins to solar radiation. Nielsen et al (1988) investigated the heat gain of subjects Page 2 of 36 
exercising in the sun and found that the net gain from the solar radiation was $125 \mathrm{~W}$ (approximately $70 \mathrm{Wm}^{-2}$ ). It was concluded that the heat load from solar radiation is not negligible.

There is much evidence that suggests that direct solar radiation should be considered as an individual radiant component, when calculating its effect on humans, rather than as a component within mean radiant temperature $\left(\mathrm{t}_{\mathrm{r}}\right)$, Blazejczyk et al (1992), Moran et al (1995), Shapiro et al (1995).

Roller and Goldman (1968) presented a theoretical model for predicting the solar heat load on humans in a radiant environment. It was found that the average absorbed radiation was $400 \mathrm{Wm}^{-2}$ for Caucasian males, for a range of environments (radiant load 616 to $808 \mathrm{Wm}^{-2}$ ). From their experiments they produced a simplified formula for determining solar radiation on a person. Further development of this model was carried out by Breckenridge and Goldman (1971). The model was evaluated using data derived from experiments with a heated copper manikin. Initially they found that the model predicted the heat loads poorly. However, when they made corrections to the equations for the absorptance and transmittance of the clothing and body area exposed to direct solar load, the predicted values were within 4 Watts (SD \pm $12 \mathrm{~W})$.

Studies by Nielsen et al (1988); Nielsen (1990); and Blazejczyk (1994) have shown that direct solar radiation has a significant effect upon human thermoregulation. However, these studies have looked at subjects exercising in the sun, rather than investigating the effects of direct solar radiation on humans with low metabolic rates. McNeill and Parsons (1999) found that existing standards for assessing hot environments (ISO 7933) did not predict well in solar conditions. If this is true of heat stress indices then it is possible that it is also true for comfort indices. The environmental parameter that is most significantly affected by solar radiation is mean radiant temperature $\left(\mathrm{t}_{\mathrm{r}}\right)$. Due to the nature of sunlight, its combination of Page 3 of 36 
UV, visible and IR radiation and in particular its directional property, traditional indices may not fully incorporate its effect in the calculation of $t_{r}$. It is therefore important to establish the effect of direct solar radiation on human thermal comfort.

\subsection{Thermal Comfort in Vehicles}

Interest within the automotive industry in improving vehicle comfort has taken the form of improving ride comfort, seating, controls and the thermal environment. Whilst there is a substantial body of work dealing with the physical aspects of sitting in a car, Brooks and Parsons (1999), Fung and Parsons (1999), Huston et al (1996) and being exposed to different terrains, Parsons and Griffin (1983), Reed and Schneider (1996), Nilsson et al (1999), the number of investigations into human thermal comfort in vehicles is limited.

Vehicles are prone to considerable fluctuations in environmental conditions; rapid changes in air temperature, solar radiation, and air movement, Temming (1980). This presents problems in the evaluation and prediction of the thermal environment in vehicles.

Tanaka et al (1992) observed that thermal sensation of vehicle occupants depends on skin temperature and the rate of change of skin temperature. They found that thermal sensation was related to the skin temperature of the face.

\subsection{Thermal radiation and comfort}

Visible radiation has a very high intensity of energy but this occurs over a very small section of the electromagnetic spectrum. It is not known whether radiation energy with different wavelength characteristics will have different effects on human perception of thermal sensation? It is also not known whether people are sufficiently sensitive to react physiologically to subtle changes in the spectral content of radiation? 
Narita et al (2001) investigated the effect of spectral content of solar radiation on the thermal sensation of the back of the hand. Subjects were exposed to three types of radiation, visible $(0.30-0.8 \mathrm{~nm})$, near infrared $(0.8-1.35 \mathrm{~nm})$ and middle infrared $(1.7-2.3 \mathrm{~nm})$. They exposed the right hand to various spectral combinations of radiation whilst the left hand was constantly irradiated with radiation encompassing the range of wavelengths used on the other hand $(0.3-2.5 \mathrm{~nm})$. It was found that the visible and middle infrared radiation were perceived to be hotter than the total wavelength condition. The radiation intensities used in this experiment were very high, 905 to $1186 \mathrm{Wm}^{-2}$ and were concentrated over a very small area. These levels of radiation resulted in high skin temperatures on the hand, 38 to $44^{\circ} \mathrm{C}$, which occurred over a very short period, $40-80$ seconds. Such high levels of solar direct radiation on to the body surface would be rare in the real world. At lower levels of total intensity such differences between the spectral properties of the radiation may not be perceptible.

This contrasted with the work of Matsui (1987), cited in Narita et al (2001), which found that subjects perceived long wavelength infrared radiation $(6-20 \mathrm{~nm})$ to be hotter than short wavelength infrared radiation $(0.72-2.7 \mathrm{~nm})$. With both radiation conditions having the same total energy intensity $\left(\mathrm{Wm}^{-2}\right)$. This difference was attributed to the different spectral properties of the skin. Radiation with a wavelength greater than $2 \mathrm{~nm}$ stimulates warm receptors $1 \mathrm{~mm}$ below the skins surface, whilst radiation less than $2 \mathrm{~nm}$ is reflected by the skins surface. It is suggested that as a result of the greater transmission of the short wavelength radiation it penetrates to a depth greater than the warm receptors, thus providing a reduced stimulus by comparison.

Ogawa et al (1991) investigated the effect of three different wavelengths of radiation with the same effective radiant temperature on the subject's skin on the sweating response of seated subjects. They compared sweating responses between non-irradiated and irradiated skin for near infrared (0.7-2.8 nm), intermediate infrared (1.5-5.8 nm) and far infrared (2.8-25 nm) 
radiation. They concluded that sweat gland activity varies with spectral change in radiation.

Both of these studies used infrared radiation. In an external environment it is unlikely that people will come into contact with such radiant heat sources. The direct heat source, that is likely to have a significant effect on a person outdoors, is the sun. Therefore it is unlikely that infrared radiation of such intensities is going to be present without considerable shortwave visible radiation. One other area of weakness is the overlapping of the infrared spectral wavelengths. This may mask some of the effects of particular wavelengths. It can be concluded therefore that the effects of spectral content of solar radiation on thermal comfort are not fully known.

The number of investigations into the effect of solar radiation on thermal comfort in vehicles using human subjects is particularly small when compared with the overall number of investigations into thermal comfort conducted in buildings. The constantly changing conditions of both the internal and external environments of the vehicles makes it particularly difficult to study. As consumers constantly demand more of their vehicles, so the need for greater understanding of thermal comfort in these complex environments must match their desire for a more thermally comfortable journey.

The aim of this paper was to investigate the effect of direct solar radiation on human thermal comfort in vehicle environments. It presents three experiments designed to establish the relationship between solar radiation and thermal sensation, in terms of intensity level and spectral content of the radiation and the effect of different glazing types.

\section{Materials and Method}

The investigation incorporated three studies; all used the same test equipment and protocol, with only the experimental condition changing.

Page 6 of 36 
Study 1 - The effect of simulated solar radiation intensity on thermal sensation.

Study 2 - The effect of spectral content of simulated solar radiation on thermal sensation.

Study 3 - The effect of glazing type on the thermal sensation of people exposed to simulated solar radiation through glazing.

\subsection{Test Facility}

A purpose built insulated and air conditioned environment was constructed which would provide a thermally neutral environment, $\mathrm{PMV}=0 \pm 0.5$, (ISO 7730: 1994). One end wall had a $45^{\circ}$ angled frame, which had, $1 \mathrm{~m} \times 1 \mathrm{~m}$ panels into which glazing panels could be fitted, Figure 1. The test chamber was divided into two separated test cells, each with a Fiat Punto car seat which was fitted to a moveable base platform, Figure 2. This base was fitted with tracking that allowed the seat to be withdrawn from the direct radiation. Fans blew air rapidly across the outside of the windows to prevent temperature build-up and hence reduce any effects of re-radiation from the window to the subject.

Insert Figures 1 and 2 here

\subsection{Solar Simulation Source}

The bank of four Solar Simulation lamps selected for the experiment were 1000 Watt metal halide, CSI lamps, manufactured by GE Lighting. These lamps produce light with a spectrum similar to that of sunlight, and have been used widely across a number of industries for this purpose, Beeson (1978), Blazejczyk et al (1992), Nilsson et al (1997). The intensity of the radiation falling on the subject was controlled by the distance of the lamps from the subject. This preserved the spectral content of the energy from the lamps. The closer the radiation source to the subject the greater the energy irradiated onto their body. 


\subsection{Physical and Physiological measurements}

A series of objective physiological measures were taken on each subject, (mean and local skin temperatures). These were recorded every ten seconds via Eltek / Grant squirrel data loggers. In addition subjects' oral temperature was measured immediately before and after the experiment. Mean skin temperature was measured using a four point method, Ramanathan (1964).

\subsection{Subjective measurements}

A subjective questionnaire was completed by the subjects (Figure 3). It was considered necessary to modify the ISO 7 point thermal sensation scale to provide a more sensitive scale to measure the effects of the solar radiation. Initial quantification of the experimental variables indicated that for $t_{r}$ in terms of direct simulated solar radiation, sensation felt would exceed +3 (Hot) on the ISO scale. The thermal sensation scale was extended a further 2 points, based upon ISO 10551 (1995) and a wider scale of thermal sensation described by Givoni (1976).

Whilst it is technically a bi-polar scale, because of the environmental conditions presented to the subjects, i.e. neutral or warmer, the full 11 point (extremely hot to extremely cold) scale was not presented. The scale used a continuous Likert rating, rather than discrete points. This allowed the subject to mark the vertical line precisely at the point which represents their thermal sensation, (e.g. +1.5 , indicates a sensation between slightly warm and warm). Subjects gave ratings of thermal sensation, comfort, stickiness and preference in terms of both overall feeling and over areas of the body.

Insert Figure 3 about here 


\subsection{Experimental Design}

Study 1 - A repeated measures within-subject design was used. Subjects were exposed to four conditions, $0,200,400$ and $600 \mathrm{Wm}^{-2}$, with $0 \mathrm{Wm}^{-2}$ being a control condition to ensure that PMV = 0 had been achieved and that the subjects were thermally neutral throughout the session when not in direct solar radiation.

Study 2 - The subjects were exposed to $400 \mathrm{Wm}^{-2}$ of simulated solar radiation for four spectral conditions, these were achieved using different types of glazing, Table 1:

Insert Table 1 about here

Each glazing type had different transmission and absorption qualities, which changed the spectrum of the radiation received by the subject from that of the simulated solar radiation source. In this study the subjects were exposed to the same level of total radiation intensity $\left(400 \mathrm{Wm}^{-2}\right)$ irrespective of its spectral content.

Study 3 - Similar to Study 2, the subjects were exposed to four spectral conditions, these were achieved using different types of glazing. The level of radiation on the subject however was determined by a constant $1000 \mathrm{Wm}^{-2}$ exposed to the outside surface of the glazing, Table 2.

Insert Table 2 about here

The presentation sequence in each study was balanced using Latin square designs to ensure that order effects were minimised. 


\subsection{Subjects}

Eight, healthy, male volunteers (Age $27.3 \pm 3.1$ ) from the Loughborough area took part in Studies, 1 and 2. In Study 3, a further eight male volunteers (Age $25.6 \pm 5.1$ ) were recruited. The subjects were paid upon completion of all conditions. Subjects wore a specified clothing ensemble of white cotton/polyester (65/35\%) long sleeve shirt, (sleeves rolled up above elbow), beige cotton/polyester (65/35\%) trousers, and the subjects wore their own under garments and shoes giving an estimated clo value of 0.7 (including seat), (ISO 7730: 1994). The seats used were of the type fitted to the 'Fiat Punto' (circa 1998).

The subject's head was shielded. This provided a level of realism as it was considered that it would be unreasonable to expect drivers and/or front seat passengers to drive directly into the sun for a long period of time without taking protective behavioural measures to reduce glare and visual discomfort. This meant that no direct radiation was exposed to their face/eyes and that the area of the body irradiated was the torso (from the neck down), arms and thighs of the subject.

\subsection{Environmental conditions}

For all studies the environmental chamber was controlled in order to maintain a constant 'neutral' environment condition, PMV $=0 \pm 0.5$ (ISO 7730) when the effect of the direct radiation was not considered. The air temperature, $\left(t_{a}\right)$, mean radiant temperature $\left(t_{r}\right)=t_{a}$ relative humidity $(\mathrm{rh} \%)$ and air velocity $\left(\mathrm{ms}^{-1}\right)$, subjects' clothing and their metabolic rate, remained 'constant' at levels that provided a neutral environment.

\subsection{Environmental Measurements}

Environmental conditions were monitored and measured throughout the experimental chamber.

- Air temperature, $\mathrm{t}_{\mathrm{a}}$ in a number of positions with thermistors, at the subject's knees, Page 10 of 36 
head height, and shaded from direct radiation

- Mean radiant temperature, $\mathrm{t}_{\mathrm{r}}$ using a $150 \mathrm{~mm}$ diameter black globe next to the subject, and one behind the subject, (shaded)

- Air velocity, $v$ with a hot wire anemometer next to the subject

- Relative humidity, rh(\%), behind the subject with a Vassala chip meter

Environmental conditions were monitored and recorded every ten seconds via Eltek / Grant squirrel data loggers.

Direct radiation was measured with a Kipp and Zonen CM11 Pyronometer. During the experiments, measurements of direct solar radiation were taken 'normal' to the subjects chest and thighs.

\subsection{Procedure}

Subjects arrived at the laboratory approximately 30 minutes prior to the experiment. They were taken to a preparation room with a neutral ambient temperature. They completed medical consent forms and were briefed on both the withdrawal criteria and the experimental procedure. Subjects had a series of six skin thermistors fitted to various body parts. The thermistors were secured via single strips of 3M Transpore tape to the subject's skin down the left hand side of the body. The thermistors were fitted into Eltek / Grant squirrel data loggers and recordings were taken every ten seconds. In addition, the subject's oral temperature was measured immediately before and after the experiment.

The subjects dressed in the standard clothing provided and sat whilst their oral temperature was taken using a mercury-in-glass thermometer. The questionnaire was explained to the subject and the first subjective questionnaire was completed to ensure that they were thermally neutral prior to undertaking the experiment. If a subject was not thermally neutral, they were left in the room until they reached a neutral state and this was ascertained by the 
completion of a further subjective questionnaire.

The solar simulation lamps were turned on for at least 30 minutes prior to the start of the experiment to allow them to reach their steady state operating conditions.

The subjects were taken into the neutral environmental test chamber. They were seated in the car seat, (out of the direct simulated solar radiation), and they completed a questionnaire to ensure that they were still feeling neutral. When both subject and experimenter were satisfied the experiment commenced and the subject's seat was pushed into the forward position into the direct solar radiation and they were handed the first experimental questionnaire to complete. This was time mark 'zero', the subject then completed a questionnaire every five minutes from this time. Subjects were asked to keep their left arm still during the experiment using the right to complete the questionnaires, which were handed to them by the experimenter. The subjects were seated in the car seat for 30 minutes.

The subjects were seated directly facing the solar simulation lamp, this resulted in their upper and lower torso, arms and upper legs being directly irradiated. After completion of the final questionnaire, administered at 30 minutes, the subject was withdrawn from the direct radiation, their oral temperature taken and a post experimental questionnaire completed.

Statistical analysis of the 30 minute ratings was carried out. Changes in mean skin temperature values were evaluated using a paired students t-test. Analysis of the subjective measures was performed using a Wilcoxon sign test. 


\section{Results}

\subsection{Study 1:The effect of radiation intensity}

\subsubsection{Environmental Conditions}

The data presented in tables 3,4 and 5 use the following legends; $t_{a}$, air temperature, $t_{g}$ globe temperature, $\mathrm{t}_{\mathrm{r}}$ mean radiant temperature derived from globe temperature (Parsons 2003 pp 97), v air velocity and rh\% relative humidity.

It can be seen from Table 3 that for all experimental conditions the predicted level of thermal comfort as calculated from ISO 7730 (1994) remained within the $0 \pm 0.5$ PMV tolerance, when $t_{r}=t_{a}$, as set a priori. Whilst, it can be seen that when the actual $t_{r}$ is placed into the thermal comfort equation, the simulated solar radiation loads change the environments from approximately neutral $(P M V=0)$ to warm $(P M V=2)$ to hot $(P M V=3)$. The introduction of a directional source of radiation, had a significant effect on the mean radiant temperature as derived from globe temperature $t_{g}$

Insert Table 3 about here

\subsubsection{Mean skin temperatures}

The subjects had a set of skin thermistors attached to their bodies, fitted to the chest, upper arm, thigh and calf. These were combined to give a weighted mean skin temperature. Figure 4 shows comparison of the mean of mean skin temperatures for all of the subjects for the four conditions. The 30 minute mark is indicated on the mean skin temperature graph. At this point the subjects completed their last questionnaire and remained in the radiation until they had completed it. For this reason there is a delay of one to two minutes before the subjects were removed from the radiation.

Insert Figures 4, 5, 6 and 7 about here

Page 13 of 36 
It can be seen that there were highly significant differences between the three radiation conditions and control condition, $p \leq 0.01$. Although there is not a significant difference between $400 \mathrm{Wm}^{-2}$ and $600 \mathrm{Wm}^{-2}(\mathrm{P}=0.12)$

A comfortable mean skin temperature for a sedentary person is around $33^{\circ} \mathrm{C}$, Gagge et al (1967). The mean of the mean skin temperatures for subjects in the thermally neutral condition (PMV $=0)$ was $32.8^{\circ} \mathrm{C}$, this is in accordance with Gagge's findings. With the addition of direct simulated solar radiation to the subject the mean skin temperature increases dramatically, by over $2^{\circ} \mathrm{C}$ for $200 \mathrm{Wm}^{-2}$. There were significant increases in mean skin temperature for both $400 \mathrm{Wm}^{-2}$ and $600 \mathrm{Wm}^{-2}$ experimental conditions. With all of the radiation conditions a rapid change in mean skin temperature can be seen over the first 10 to 12 minutes of exposure with a plateau beyond that. This would indicate that the subjects were in a steady state of thermoregulation. The differences between the radiation levels could be considered of significance in psycho-physiological terms. This is confirmed when considering individual subject data, where rank order of radiation intensity showed consistent trends and the paired t test showed significant differences between conditions.

\subsubsection{Thermal sensation}

Subjects recorded their thermal sensation every five minutes, with the end vote (30 minutes) of each subject being taken for analysis. There were significant differences between the three radiation conditions, $\mathrm{p} \leq 0.05$, with the exception of $400 \mathrm{Wm}^{-2}$ and $200 \mathrm{Wm}^{-2}(\mathrm{p}=0.1)$ and $200 \mathrm{Wm}^{-2}$ and $0 \mathrm{Wm}^{-2}(\mathrm{p}=0.2)$. There appears to be little difference perceived by the subjects between 200 and $400 \mathrm{Wm}^{-2}$ of radiant energy. Thermal sensation votes indicate how warm the subjects feel in the simulated solar radiation environment. It can be seen in Figure 5 that, on average, after 30 minutes of exposure, subjects were approximately one sensation scale point warmer for each $200 \mathrm{Wm}^{-2}$ of direct radiation that they were exposed to. All subjects voted the $600 \mathrm{Wm}^{-2}$ condition to give the highest sensation. 
Figure 6 shows the mean thermal comfort plots for all of the subjects for the four experimental conditions. This shows clearly an increase in the level of discomfort felt by the subjects between each of the conditions.

It can be seen that there were significant differences between all but one of the conditions, $p$ $\leq 0.05$. There was not a significant difference between $400 \mathrm{Wm}^{-2}$ and $600 \mathrm{Wm}^{-2}(\mathrm{p}=0.2)$

Figure 7 show the stickiness votes, it shows clearly an increase in the level of discomfort felt due to stickiness by the subjects between each of the conditions. There were significant differences $(p \leq 0.05)$ between all but two of the radiation conditions, $200 / 400 \mathrm{Wm}^{-2}(p=0.2)$ and $0 / 200 \mathrm{Wm}^{-2}(\mathrm{p}=0.2)$

When a subject becomes warm, some sweating will occur. The interaction between the sweat, clothing and seat materials will cause stickiness. Stickiness level is related to discomfort in warm environments. Ratings of stickiness can therefore provide an indication of thermal discomfort. In the experiment the level of stickiness rose consistently with increases in radiation intensity.

\subsection{Study 2: The effect of spectral content of radiation}

\subsubsection{Environmental Conditions}

It can be seen from Table 4 that for all experimental conditions the predicted level of thermal comfort as calculated from ISO 7730 (1994) remained within the $0 \pm 0.5$ PMV tolerance, when $t_{r}=t_{a}$, as set a priori. Whilst it can be seen that when the actual $t_{r}$ is placed into the thermal comfort equation, (an estimation of $t_{r}$ based upon corrected $t_{g}$ - Parsons, 2003), the simulated solar radiation loads change the environments from around 'slightly warm' / 'warm' $(P M V=1.5)$ to 'warm' $(P M V=2)$. The introduction of a directional source of radiation, with 
different spectral contents, had no significant effect on the mean radiant temperature as calculated from globe temperature $t_{g}$, for tinted laminate, PPB clear, and tinted monolithic glazing. Values for clear laminate glazing were slightly higher.

Insert Table 4 about here

\subsubsection{Mean skin temperatures}

Figure 8 shows comparison of the mean of mean skin temperatures for all of the subjects for the four conditions.

Insert Figures 8, 9, 10 and 11 grouped here

There was no significant difference between any of the spectral conditions for mean skin temperature.

\subsubsection{Thermal sensation}

There were no significant differences between glazing types for thermal sensation, thermal comfort, stickiness or preference votes, (Figures 9, 10 and 11). It is clear that there was an increase in thermal sensations felt by the subjects during the exposure but the increases followed the same pattern for each of the four spectral conditions.

\subsection{Study 3:The effect of glazing type}

\subsubsection{Environmental Conditions}

It can be seen from Table 5 that for all experimental conditions the predicted level of thermal comfort as calculated from ISO 7730 (1994) remained within the $0 \pm 0.5$ PMV tolerance, when $t_{r}=t_{a}$, as set a priori. Whilst, it can be seen that when the actual $t_{r}$ is placed into the thermal comfort equation, the simulated solar radiation loads change the environments from 
around 'slightly warm' / 'warm' (PMV = 1.5) to 'warm' (PMV = 2). The TL and PPB glazing had similar $\mathrm{t}_{\mathrm{g}}$ and $\mathrm{t}_{\mathrm{r}}$ temperatures, but clear monolithic $(\mathrm{CM})$ and clear laminate $(\mathrm{CL})$ glass had slightly higher values.

Insert Table 5 about here

\subsubsection{Mean skin temperatures}

Figure 12 shows the comparison of the mean of mean skin temperatures for all of the subjects for the four conditions. The addition of direct simulated solar radiation to the subjects resulted in the mean skin temperature increasing by approximately $2^{\circ} \mathrm{C}$ over the 30 minutes for the clear monolithic $(C M)$ and clear laminate $(C L)$ glazings. Whilst the mean $t_{s k}$ response for subjects exposed to the tinted laminate $(T L)$ and PPB glazing rose by over $3^{\circ} \mathrm{C}$. There were significant differences $(P<0.01)$ between all of the mean skin temperatures with the exception of clear monolithic $(C M)$ and clear laminate $(C L)$ and tinted laminate $(T L)$ and PPB glazing combinations.

Insert Figures $12,13,14$, and 15 (grouped) about here

\subsubsection{Thermal sensation}

It can be seen in Figure 13 that, on average across subjects, after 30 minutes of exposure, they were between 'slightly warm' and above 'hot' in terms of sensation for the glazing types that they were exposed to. There were significant differences $(P<0.05)$ between all of the sensations with the exception of CM / CL and TL / PPB glazing combinations. There was also a trend towards a difference between $C L$ and $C M,(P=0.07)$.

Subjects indicated that they were between 'slightly uncomfortable' and 'uncomfortable' over the four conditions, Figure 14. There were significant differences $(P<0.05)$ between all of 
the sensations with the exception of CM / CL and TL / PPB glazing combinations. There was also a trend towards a difference between $C L$ and $T L$ glazing, $(P=0.09)$.

In the experiment the subjects felt between 'slightly sticky' PPB and TL glazings and 'sticky' for the $C M$ and $C L$ glazings, Figure 15 . There were significant differences $(P<0.05)$ between all of the sensations with the exception of TL / CL and PPB / TL glazing combinations. There was also a trend towards a difference between $C L$ and $T L$ glazing, $(P=0.09)$.

Figures 16, 17 and 18 show the end vote discomfort curves for Studies 1, 2 and 3 . It can be seen from the standard deviations on the intensity discomfort curve that the subjects' sensation votes had a wide range of variation around $400 \mathrm{Wm}^{-2}$. There were a number of different individual responses to the three levels of direct radiation. However, taken over all subjects, it can be clearly seen that there is a significant difference between the sensations felt at each level.

Insert Figures 16, 17 and 18 (grouped) about here

\section{Discussion}

\subsection{Environmental conditions}

Tables 3,4 and 5 show that the required level of PMV, $0 \pm 0.5$, (with $t_{r}=t_{a}$ ) was maintained for all conditions. This means that the thermal discomfort felt by the subjects was as a result of the discomfort produced by the direct simulated solar radiation.

In Study 2, there was a slightly higher globe and subsequently derived mean radiant temperature measured in the clear laminate glazing condition. This may possibly be due to the position of the lamps relative to the glazing. To ensure that $400 \mathrm{Wm}^{-2}$ of total energy was received by the subject, the distance of the lamps was adjusted. For this condition, the lamps Page 18 of 36 
were only $600 \mathrm{~mm}$ from the glazing surface, to compensate for the lower level of transmission of visible radiation. This meant that there was some heating of the glazing, despite the use of fans to cool the exterior of the glazing. This is the only environmental variable which differed between conditions.

\subsection{Study $1:$ Intensity effects}

The weighted mean skin temperatures for the four conditions were found to be significantly different, $\mathrm{P}<0.009$, with the exception of 0 and $200 \mathrm{Wm}^{-2}$. It can also be seen that skin temperature starts to rise immediately upon exposure to the simulated solar radiation and it reaches a steady state at around 12 minutes for the three levels of applied radiation. The initial increase in mean skin temperature corresponds well with that of the subjective responses. However, the subjective responses continue to rise over the last 15 minutes of the experiment.

The local skin temperatures measured on the chest are significantly higher than those measured on the other sites of the body. This provided the main component for the increase in mean skin temperature.

The thermal sensation votes showed an increase in the discomfort felt by the subjects for all three radiation levels. Interestingly, there was not a significant increase in thermal sensation felt by the subjects between the $200 \mathrm{Wm}^{-2}$ and $400 \mathrm{Wm}^{-2}$ conditions. This can be seen in the large standard deviation of the actual mean votes (AMV) at $400 \mathrm{Wm}^{-2}$ (Figure 16). This suggests that between these levels of radiation some subjects could not easily perceive a significant difference between the two sensations felt. This compares markedly with physiological measures, which show that there was a $0.8^{\circ} \mathrm{C}$ increase in the mean skin temperature, which was highly significant $(P<0.001)$. However, it can be seen that the mean end discomfort curve, Figure 16, that there is a clear trend which indicates that for an input of 
direct radiation of $200 \mathrm{Wm}^{-2}$ there is a sensation increase of around 1 scale unit.

The mean thermal comfort votes followed a similar trend to the thermal sensation votes. Again there was a large standard deviation at $400 \mathrm{Wm}^{-2}$ suggesting that this is a transitional point for some subjects. This may be attributed to a sensation of pleasantness felt by the subjects exposed to the low to medium levels of radiation. They interpret the intensity of the sensation of warmth, but it may in fact be considered by the subjects to be comfortable and acceptable. This complements findings on the effects of short wave radiation on people outdoors (Spagnolo and de Dear, 2003; Matzarakis et al, 1999)

\subsection{Study 2:Spectral effects}

The weighted mean skin temperatures for the four conditions were found not to be significantly different. The mean responses show that there is no difference in the physiological responses of the subjects to the total energy of $400 \mathrm{Wm}^{-2}$ with four different spectral contents.

Figure 9 shows that thermal sensation rates increased over the session for all spectral radiation conditions. There was no significant difference in the thermal sensations felt by the subjects between any of the spectral conditions. The mean thermal comfort votes followed a similar trend to the thermal sensation votes, with the level of discomfort felt by the subjects increasing during the exposure. There was no statistical difference between any of the conditions.

The effect of the spectral properties of the simulated solar radiation had little or no effect on the thermal sensation of the subjects. This contrasted with the experiments of Narita et al (2001) and Ogawa et al (1991) where changes in physiological response were found for radiation of different spectral properties. The focus of previous studies had been to irradiate 
small localised areas of the body, often with very high levels of simulated solar radiation. This may explain the difference in conclusions between these studies and this current study. The spectral properties of solar radiation may indeed have an effect on thermal sensation and perception if the radiation intensity is sufficiently high, in excess of $1000 \mathrm{Wm}^{-2}$. From a practical perspective it is unlikely that people will ever be exposed to these levels of solar radiation, other than in the most extreme and hostile environments on the planet. Narita et al (2001) found that the effects of the spectral properties of the radiation were not as strong at the lower intensities $\left(<950 \mathrm{Wm}^{-2}\right)$. This finding and those of this current study indicate that radiation of different spectral properties at lower, but more realistic, levels would have little or no effect on thermal sensation.

All of the subjects' physiological and psychophysical responses corresponded well with those observed in Study 1. The thermal sensations of the subjects for $400 \mathrm{Wm}^{-2}$ of energy of different spectral contents were similar to those for $400 \mathrm{Wm}^{-2}$ measured in Study 1 . This (i.e. 30 minutes sensation rate around 'warm') leads to the conclusion that it is the total intensity of energy rather than the spectral content that affects a person's thermal psychophysiological state.

\subsection{Study 3: Glazing effect}

The weighted mean skin temperatures for all but two of the compared conditions were significantly different, $(\mathrm{P} \leq 0.01)$. But between the paired conditions $\mathrm{CL} / \mathrm{CM}$ and $\mathrm{TL} / \mathrm{PPB}$ there was no difference. This was due to the similar transmission qualities of the glazing pairs; CL / CM and TL / PPB; which resulted in similar levels of radiation falling on the subjects, CL $\left(577 \mathrm{Wm}^{-2}\right)$ / CM $\left(628 \mathrm{Wm}^{-2}\right)$ and TL $\left(339 \mathrm{Wm}^{-2}\right)$ / PPB $\left(308 \mathrm{Wm}^{-2}\right)$. As with Studies 1 and 2 there is an immediate increase in the skin temperature upon exposure, reaching a steady state at around 12 minutes. 
The mean responses, Figure 12, show that there is no difference in the physiological responses of the subjects to radiation of similar intensity. This suggests that whilst physiological responses are a good indicator of thermal state, they cannot be relied upon to provide a definitive response when there is a difference of less than $100 \mathrm{Wm}^{-2}$ or less.

The thermal sensation votes, showed that there was a significant increase in the sensations felt by the subjects for the CL and CM conditions when paired against both the PPB and TL glazing conditions, $(P \leq 0.03)$.

It can be seen that the greater the reduction of transmitted radiation to the vehicle occupant the lower, (cooler), the thermal sensations that are felt by them. With conditions $\mathrm{CM}$ and $\mathrm{CL}$ a considerably greater level of radiation reached the subject than in the TL and PPB conditions (Table 5). This is mirrored in their thermal sensation responses, (Figure 18). This concurs with Bohm et al (1997) where they predicted improved environmental conditions in the occupant space using glazing that reduces the level of solar radiation.

If the level of sensation felt by the subjects is corrected for a single scale point (radiation energy / mean sensation vote), Table 6 , then the level of radiation required to produce an increase of 1 scale unit for each glazing can be seen.

Insert Table 6 about here

This would suggest that for all but the PPB Clear glazing condition the mean scale response to the level of radiation is $196 \mathrm{Wm}^{-2}$. This corresponds well with the energy per scale point found in the intensity experiment, (Study 1). PPB Clear glazing showed a slightly higher response to the radiation level than was experienced in the other conditions. This may be due to the wide range of individual responses to the level of radiation, ranging from 0.45 
between neutral and slightly warm, and 2.80 , nearly hot on the sensation scale. This would suggest that at the lower levels of direct solar radiation the subject could not so clearly perceive the sensations they felt.

Across all three studies it was found that there was no significant difference between local body sensations and the overall sensation felt by the subjects. There was a tendency for the lower legs and feet to be slightly cooler than the upper regions of the body. This would be due to these parts of the body being shielded from the direct radiation. It is considered that the overall sensation vote provided a good indication of local body sensation.

\section{Conclusions}

1. For the conditions tested, a linear relationship was found between the level of simulated solar radiation and thermal sensation rating on the ISO thermal sensation scale. An increase in thermal sensation of 1 scale unit was found for an increased exposure of around $200 \mathrm{Wm}^{-2}$ of radiation to the body.

2. For exposure of $400 \mathrm{Wm}^{-2}$ of simulated solar radiation to the body, the spectral content of the radiation has no effect on thermal sensation that is of practical significance.

3. For an exposure of $1000 \mathrm{Wm}^{-2}$ of simulated solar radiation on the exterior surface of four glazing types, subjects were exposed to radiation over a range of levels and spectral content. In those conditions the level of the radiation and not the spectral content determined the thermal sensation response.

4. The conclusion that thermal sensation is determined mainly by solar radiation level at the position of the subject is supported by the results for ratings of 'uncomfortable' and 'stickiness' as well as for local parts of the body.

5. Mean skin temperature measurements supported the finding that solar radiation level 
is the main determinant of thermal comfort.

\section{Acknowledgements}

This work was conducted as part of Brite Euram funded project BRPR-CT97-0450 The Authors would like to acknowledge the support and help provided by Fiat, Pilkington, Renault, Rover, Splintex, Saint Gobain and the University of Warwick.

\section{References}

Beeson, E J G (1978) The CSI lamp as a source of radiation for solar simulation, Lighting Research and Technology, Vol. 10, No 3, pp 164 - 166

Blazejczyk, K (1994) Changes of skin temperature and body heat content in fluctuating outdoor climate, 6th International Conference on Environmental Ergonomics, Conference Proceedings, Montebello, Canada Eds Frim, J, Ducharme, M.B., and Tikuissi, P pp 226-227

Blazejczyk, K, Nilsson, H and Holmér I (1993) Solar heat load on man (review of different methods of estimation), International Journal of Biometeorology Vol 37: pp 125 - 132

Bohm M, Noren, O, Holmér I and Nilsson H (1997) Special glazing to improve the thermal climate in cabs. In: Proceedings of the $4^{\text {th }}$ International Conference and Exhibition, Comfort in the automotive industry, recent developments and achievements pp $163-172$

Breckenridge, J R and R F Goldman (1971) Solar heat load in man, J Appl Physiol 31(5): pp $659-663$

Brooks, J E and K C Parsons (1999) An ergonomics investigation into human thermal comfort using an automobile seat heated with encapsulated carbonized fabric (ECF), Ergonomics 42(5): pp $661-673$

Fung, W and Parsons, K C (1996) Some investigations into the relationship between car seat cover materials and thermal comfort using human subjects, Journal of coated fabrics, Vol 26 , pp $147-175$

Gagge, A P, Stolwijk, J A and Hardy, J D (1967) Comfort and thermal sensations and associated physiological responses at various ambient temperatures, Environmental research 1(1): pp 1 - 20

Givoni, B (1976) Man, climate and architecture, New York : Van Nostrand Reinhold

Huston, D R, Choukalos, C, Tranowski, J P, and Weisman, J (1996) Field measurements of 
seated vibrations, Society of Automotive Engineers, USA 960477

Hoppe, P. (1999). "The physiological equivalent temperature - a universal index for the biometeorological assessment of the thermal environment." International Journal of Biometeorology 43(2): 71-75.

ISO Standard 7730 (1994) Moderate thermal Environments - Determination of the PMV and PPD Indices and Specification of the Conditions for thermal Comfort, Geneva: International Standards Organisation

ISO 10551: (1995) Ergonomics of the thermal environment -- Assessment of the influence of the thermal environment using subjective judgement scales, Geneva: International Standards Organisation

Madsen T, Olesen, B and Reid, K (1992) New methods for evaluation of the thermal environment in automotive vehicles, ASHRAE Transactions Vol. 92 part 1, pp 38 - 54

Madsen, T L, Olesen, B W, and Kristensen, N K (1984) Comparison between operative and equivalent temperature under typical indoor conditions, ASHRAE Transactions, Vol 90, Part $1, \mathrm{pp} 1077-1090$

Matsunaga, K, Sudo, F, Tanabe, S, and Madsen, T L (1993) Evaluation and measurement of thermal comfort in the vehicles with a new thermal manikin, 931958, Society of Automotive Engineers

Matzarakis, A., H. Mayer, et al. (1999). "Applications of a universal thermal index: physiological equivalent temperature." International Journal of Biometeorology 43(2): 76-84.

McNeill, M B and Parsons, K C (1999) Appropriateness of international heat stress standards for use in tropical agricultural environments, Ergonomics, Volume 42, Number 6, pp 779 797

Moran, D, Shapiro Y, Epstein Y, Burstein R, Stroschein L, and Pandolf, K B (1995) Validation and adjustment of the mathematical prediction model for human rectal temperature responses to outdoor environmental conditions. Ergonomics 38(5) : pp 1011 - 1018

Narita, C, Tanabe, S Y Ozeki and Konishi, M (2001) Effects of spectral property of solar radiation on thermal sensation at the back of hands." Moving thermal comfort Standards into the 21st century, conference proceedings: pp $393-400$

Nielsen, B (1990) Solar heat load: heat balance during exercise in clothed subjects, European Journal of Applied Physiology 60(6): pp 452 - 456

Nielsen, B, Kassow, K and Aschengreen, F E (1988) Heat balance during exercise in the Page 25 of 36 
sun, European Journal of Applied Physiology 58(1-2): pp 189 - 196

Nilsson H, Holmér I, Bohm M, and Noren, O (1997) Equivalent temperature and thermal sensation - comparison with subjective measurements, Proceedings of the 4th International Conference Comfort in the Automotive Industry, Recent Developments and Achievement, ATA conference, Bologna, Italy

Nilsson, H, Holmér, I, Bohm, M and Noren, O (1999) Definition and theoretical background of the equivalent temperature, 99A4082, ATA conference, Florence, Italy

Ogawa, T, Sugenoya, J, Ohnishi, N, Natsume, K, Ochiai, M, Nishida, M, Shinoda, N, Katoh, $\mathrm{K}$, and Imamura, R (1991) Dynamic sweating response of man to infrared irradiation in various spectral regions. International Journal of Biometeorology 35: 18 pp $18-23$

Parsons K C, and Entwistle, D (1983) An investigation into the thermal of motor car drivers. In: Kurenna Coombes (ed) Proceedings of the Ergonomics Society Conference pp $71-75$. ISBN 0-85066-252-4

Parsons, K C and Griffin, M J (1983) Method for predicting passenger vibration discomfort. Society of Automotive Engineers Technical Paper Series 831029

Parsons, K C (1992) A thermal model of a car driver. Proceedings of the 2nd International Conference on Vehicle Comfort. PP 323 - 332. Associazione techica Dell'Automoblie, Bologna, Italy

Parsons, K C (2003) Human Thermal Environments, Taylor \& Francis. London. ISBN: 0415237920, pp $248-256$

Ramanathan, $\mathrm{N} L$ (1964) A new weighting system for mean surface temperature of the human body, J Appl Physiol 19(3): pp 531 - 533

Roller, W L and R F Goldman (1968) Prediction of solar heat load on man, J Appl Physiol 24(5): pp $717-721$

Reed, M P and Schneider L W (1996) Lumber support in auto seats: conclusions from a study of preferred driving posture, Society of Automotive Engineers, USA 960477

Rohles, F H and Nevins, R G (1971) The nature of thermal comfort in sedentary man, ASHRAE journal No. 2191 RP-43

Rohles, F H and Wallis S B (1979) Comfort Criteria for Air conditioned automotive vehicles, Society of Automotive Engineers. INC, 790122

Shapiro, Y, Moran, D, Epstein Y, Stroschein, L, and Pandolf, K B (1995) Validation and adjustment of the mathematical prediction model for human sweat rate responses to outdoor

Page 26 of 36 
environmental conditions. Ergonomics 38(5): pp 981 - 986

Spagnolo, J. and R. de Dear (2003). "A field study of thermal comfort in outdoor and semioutdoor environments in subtropical Sydney Australia." Building and Environment 38(5): pp 721-738.

Tanaka, H, Kilada, M, Taniguchi, Y, Ohno, Y, Shinagawa, T and Aoki, H (1992) Study on car air conditioning system controlled by car occupants' skin temperature - Part 2: Development of a new air conditioning system, 920170, Society of Automotive eng

Temming, J (1980) Comfort requirements for heating, ventilation and air conditioning in motor vehicles, Research and Development Division, Volkswagenwerk AG 
Figure 1 Schematic of the test chamber, showing angled end wall and overall dimensions

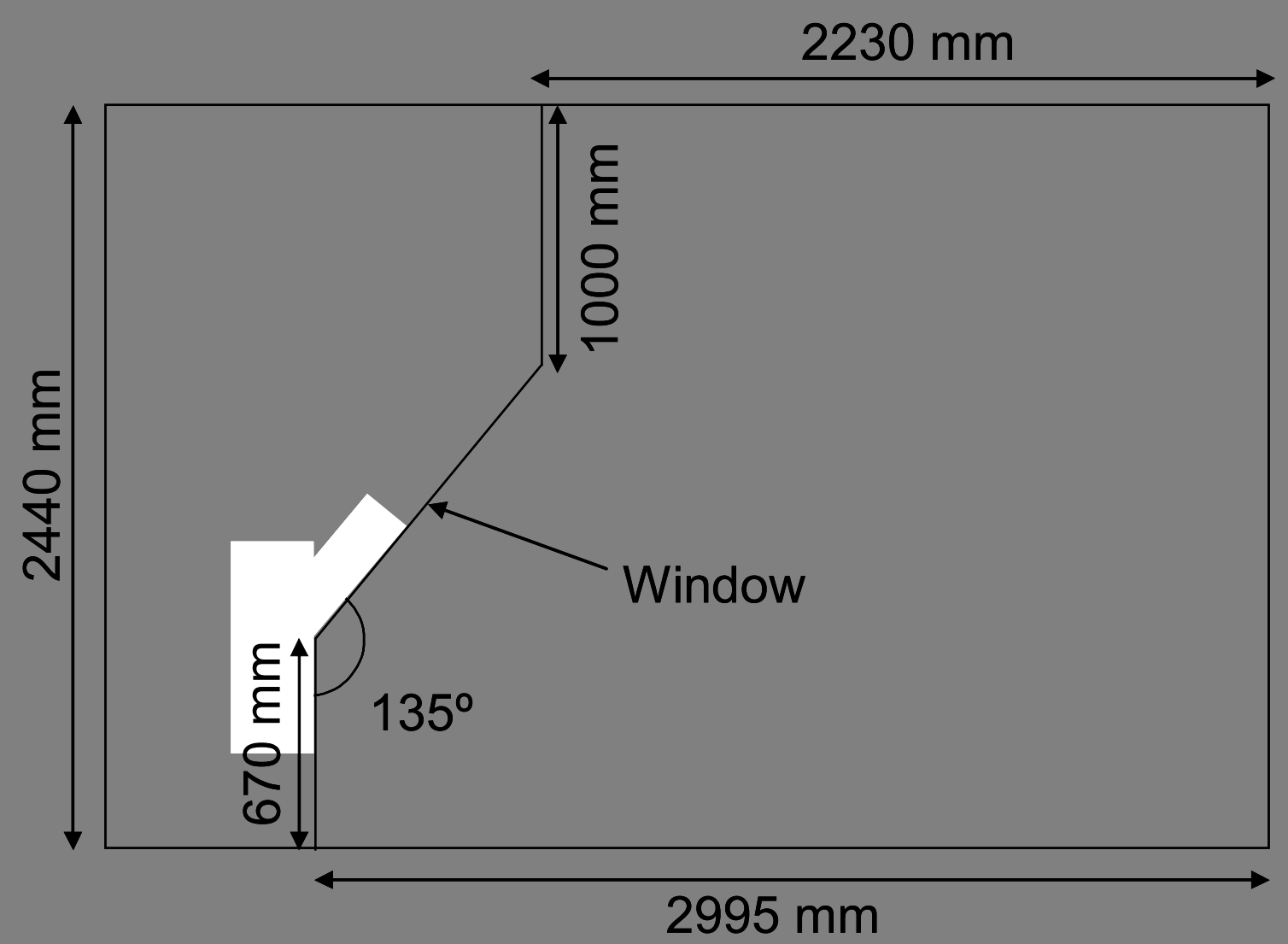


Figure 2 Plan view of the test chamber showing position of the subjects seats before and during the experiment

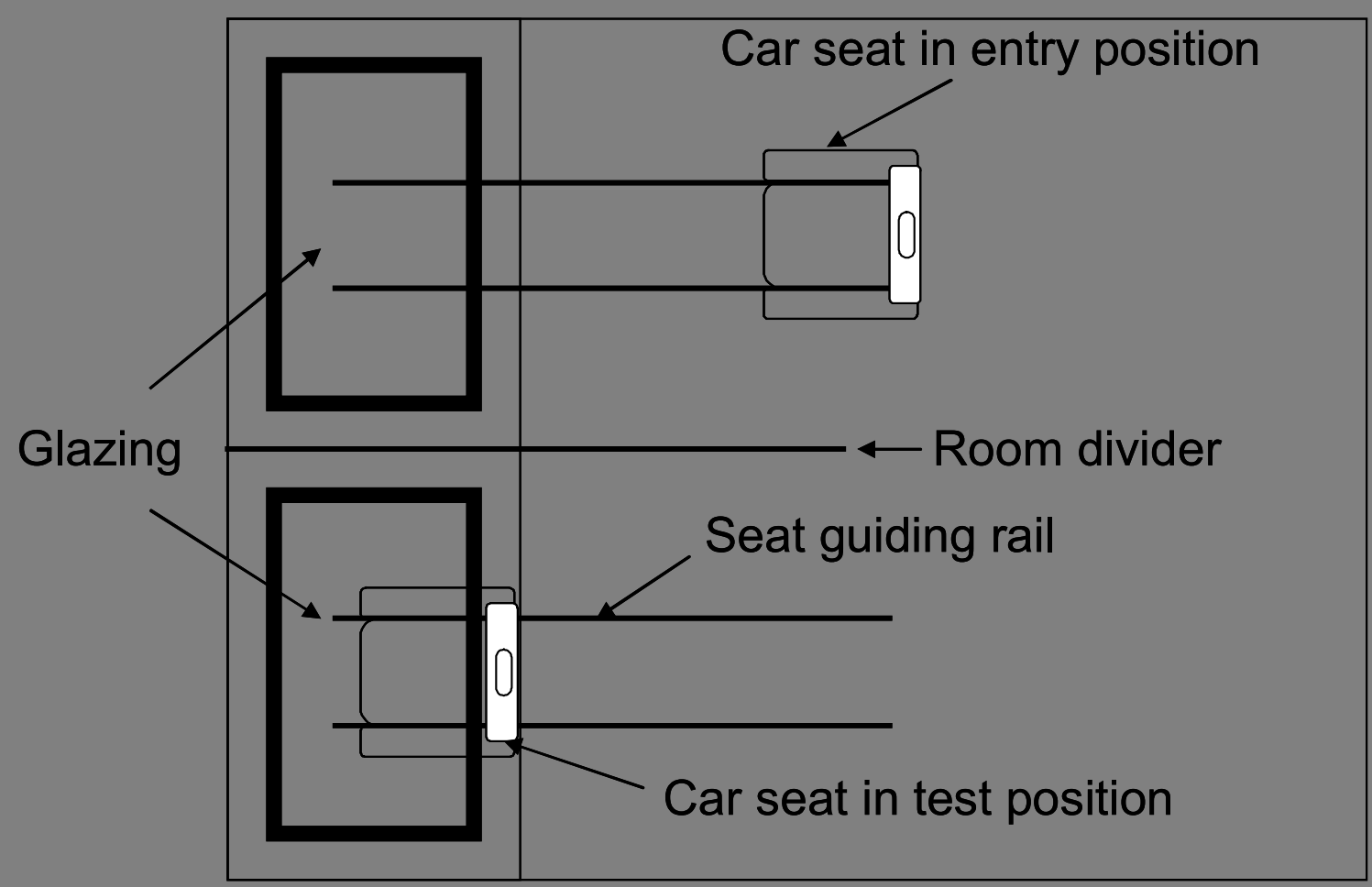


Figure 3 - Subjective questionnaire

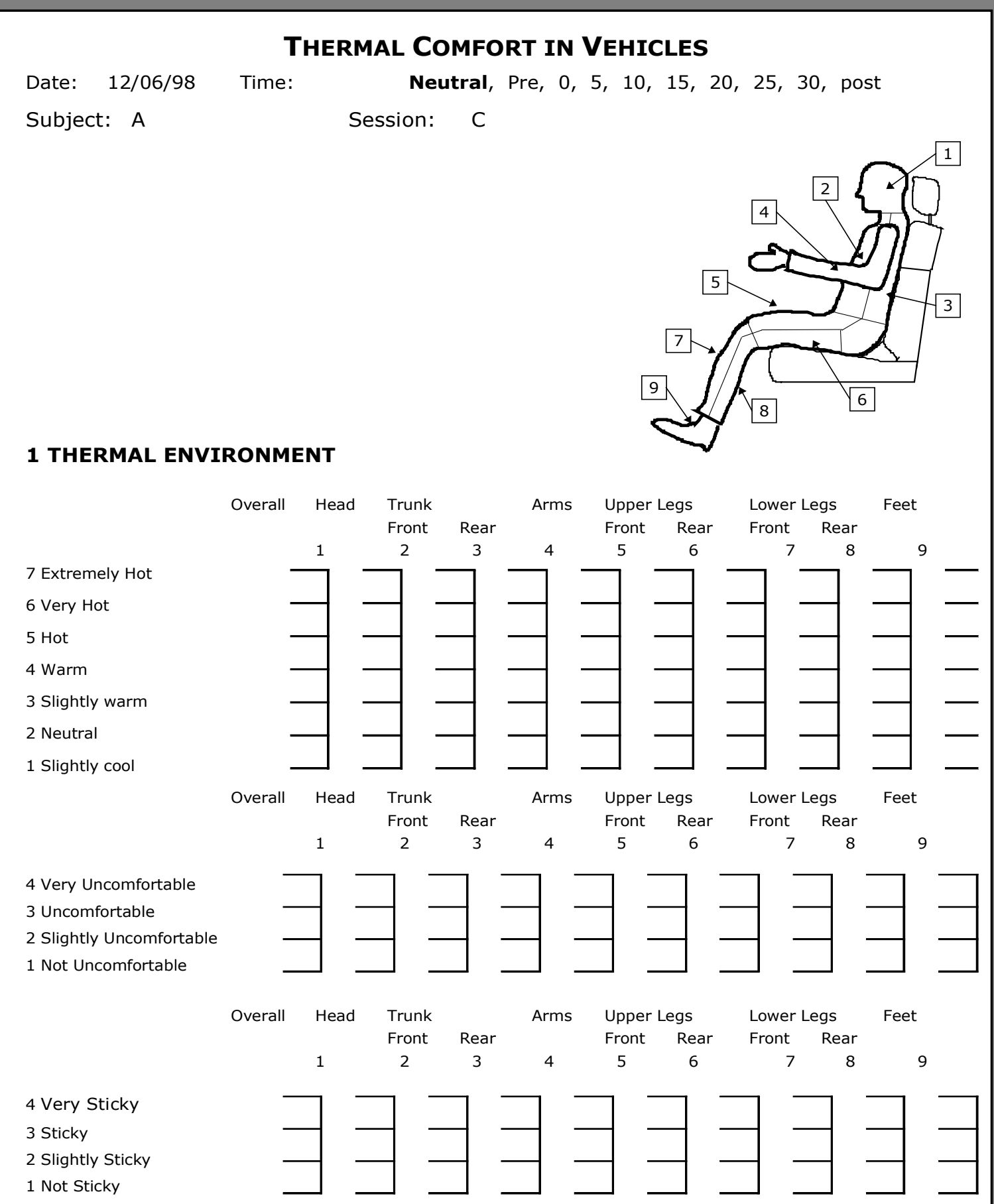

2. Please indicate how YOU would like to be NOW:

Warme

No change

Cooler 

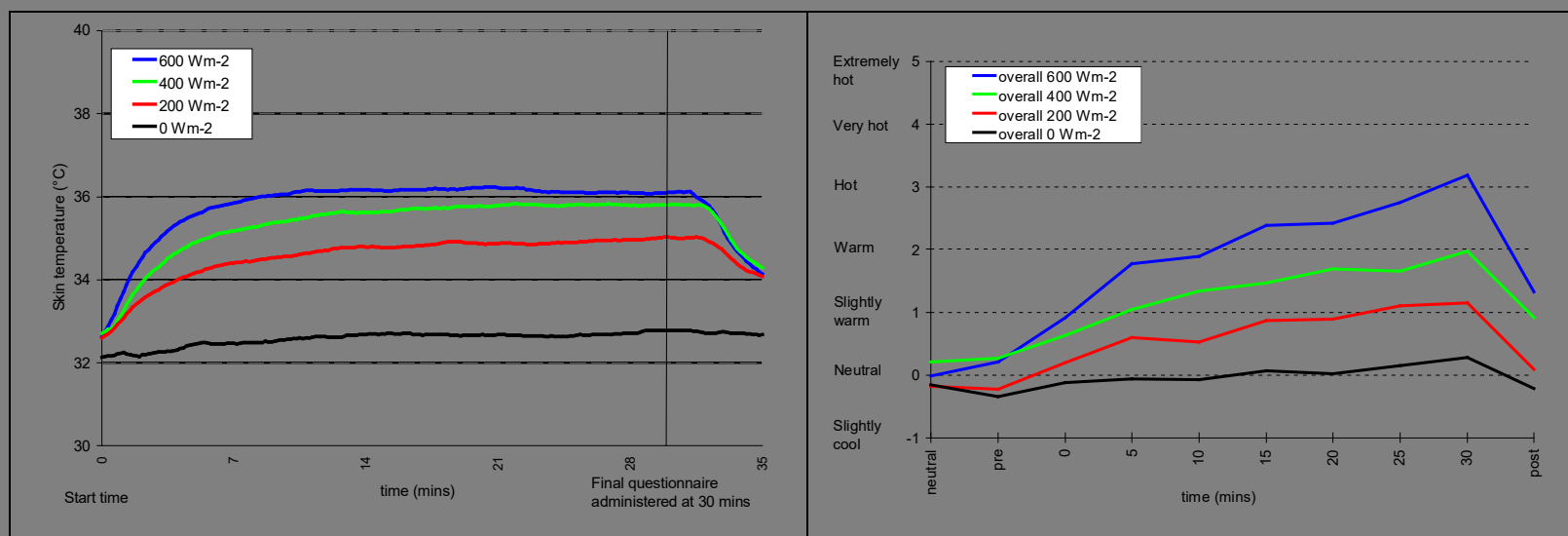

Figure 4 Mean of mean skin temperatures $t_{\text {sk }}$ for 4 different Simulated Solar radiation intensities from 0 to 30 minutes $(n=8)$

Figure 5 Mean overall thermal sensation graph for AMV for 4 different Simulated Solar radiation intensities $(n=8)$

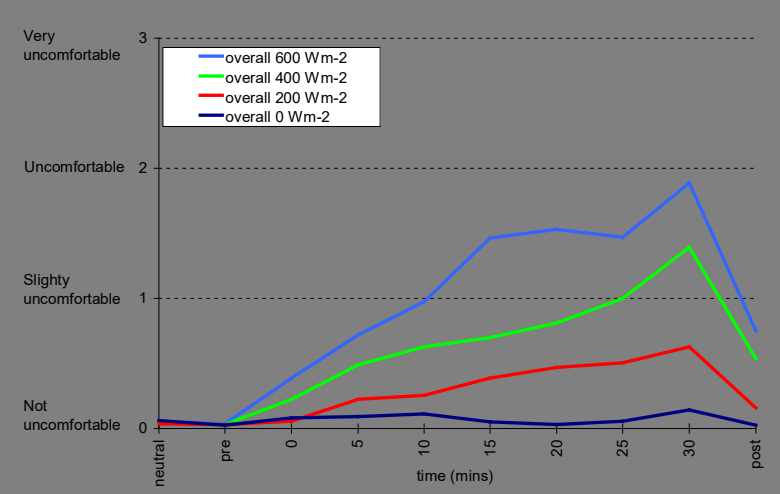

Figure 6 Mean overall thermal comfort graph for AMV for 4 different Simulated Solar radiation intensities $(n=$ 8)

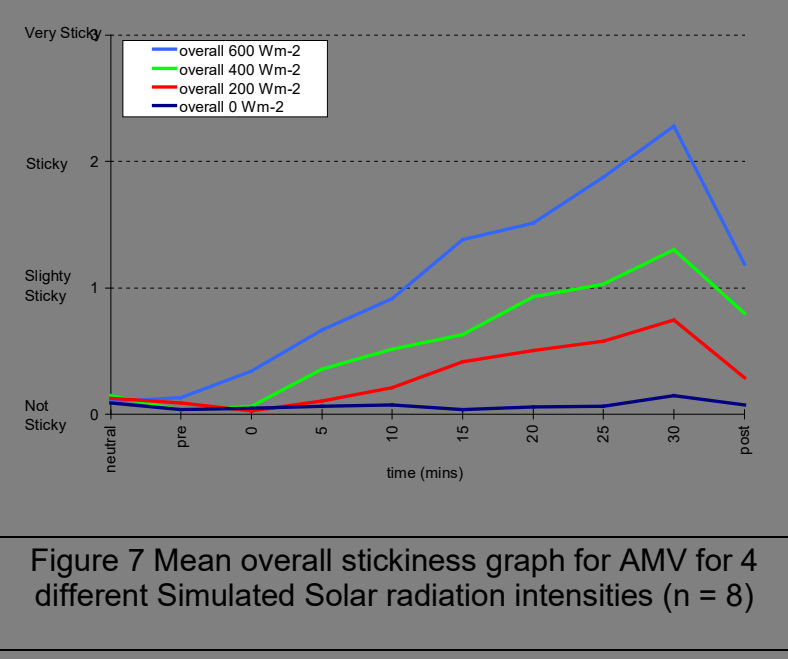




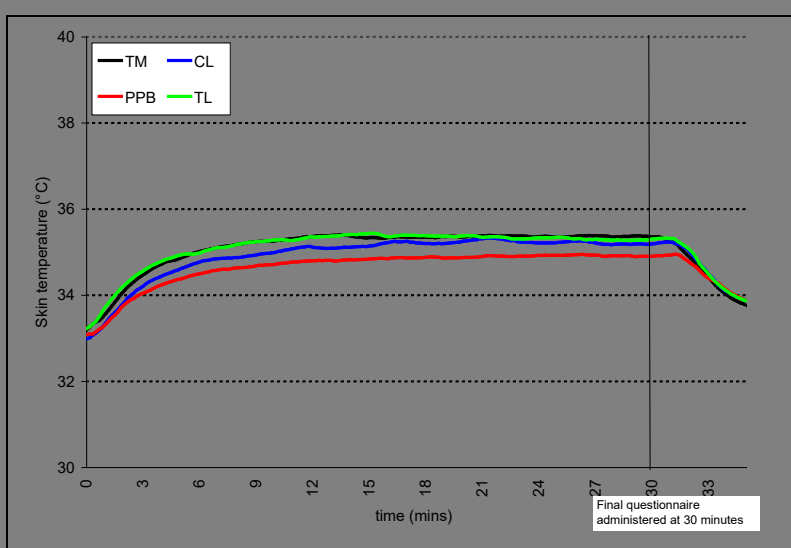

Figure 8 Mean of mean skin temperatures $t_{\text {sk }}$ for 4 different spectral contents of simulated solar radiation at a total intensity of $400 \mathrm{~W} \mathrm{~m}^{-2}$ from 0 to 30 minutes ( $\mathrm{n}$ $=8)$

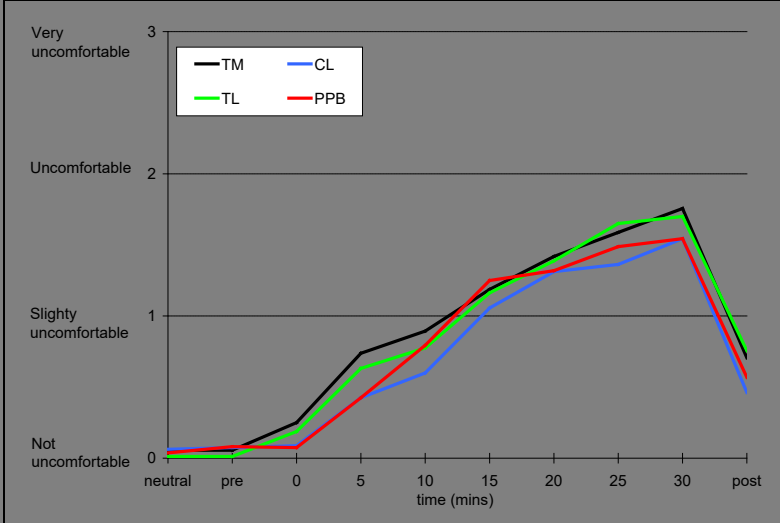

Figure 10 Mean overall thermal comfort graph for AMV for 4 different spectral contents of simulated solar radiation at a total intensity of $400 \mathrm{~W} \mathrm{~m}^{-2}(\mathrm{n}=8)$

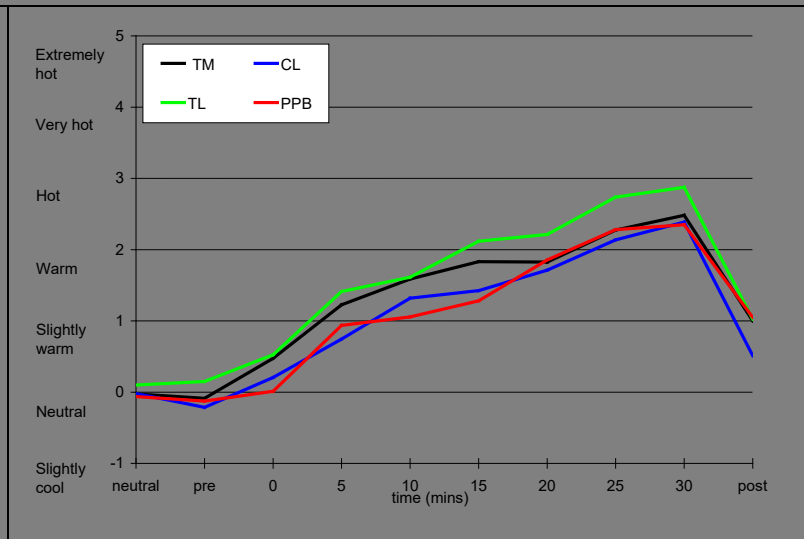

Figure 9 Mean overall thermal sensation graph for AMV for 4 different spectral contents of simulated solar radiation at a total intensity of $400 \mathrm{~W} \mathrm{~m}^{-2}(\mathrm{n}=8)$

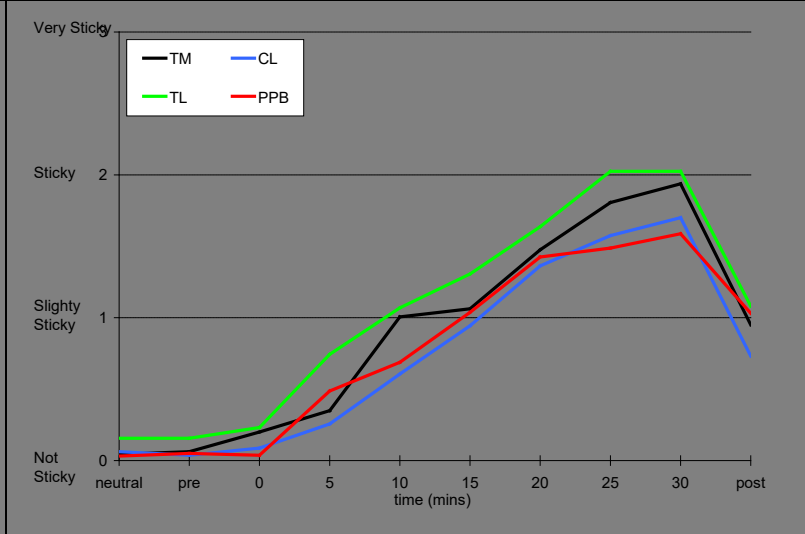

Figure 11 Mean overall stickiness graph for AMV for 4 different spectral contents of simulated solar radiation at a total intensity of $400 \mathrm{~W} \mathrm{~m}^{-2}(\mathrm{n}=8)$ 


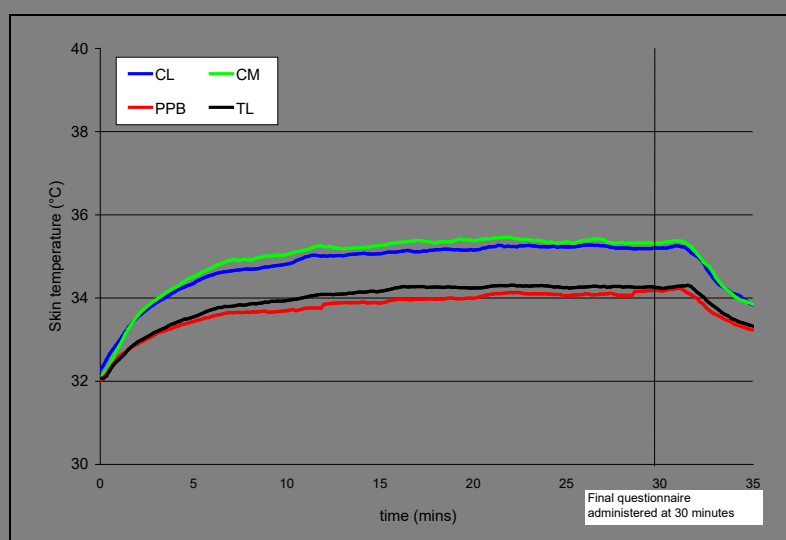

Figure 12 Mean of mean skin temperatures $t_{\text {sk }}$ for 4 different glazing conditions with a simulated solar radiation load of $1000 \mathrm{~W} \mathrm{~m}^{-2}$ from 0 to 30 minutes $(n=$ 8)

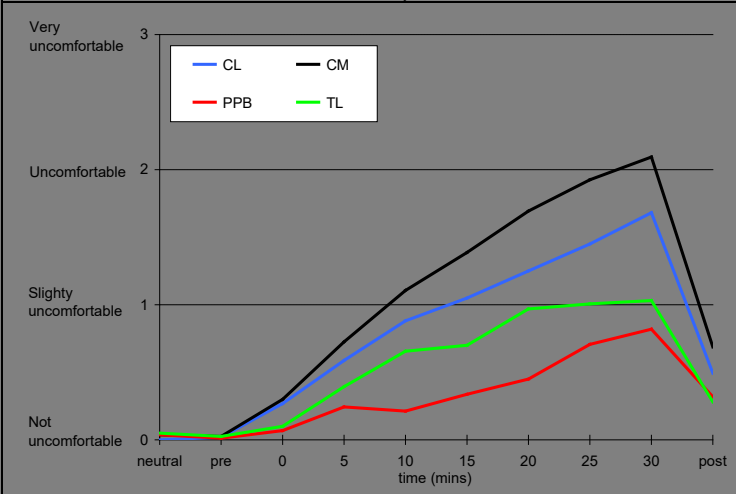

Figure 14 Mean overall thermal comfort graph for AMV for 4 different glazing conditions with a simulated solar radiation load of $1000 \mathrm{~W} \mathrm{~m}^{-2}(n=8)$

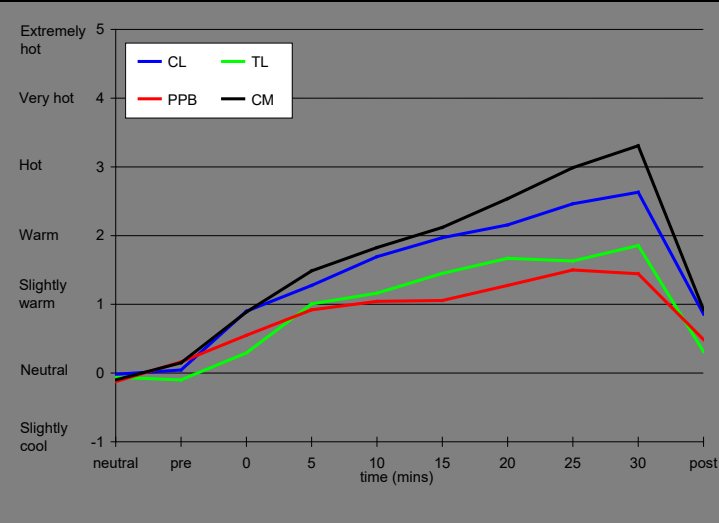

Figure 13 Mean overall thermal sensation graph for AMV for 4 different glazing conditions with a simulated solar radiation load of $1000 \mathrm{~W} \mathrm{~m}^{-2}(n=8)$

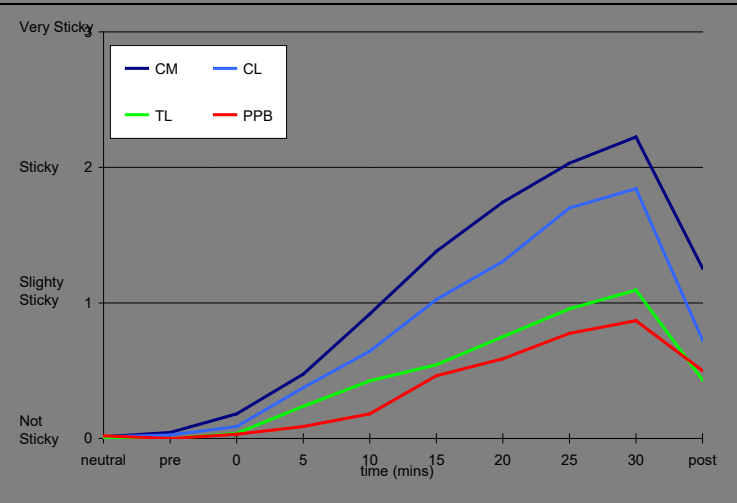

Figure 15 Mean overall stickiness graph for AMV for 4 different glazing conditions with a simulated solar radiation load of $1000 \mathrm{~W} \mathrm{~m}^{-2}(n=8)$ 

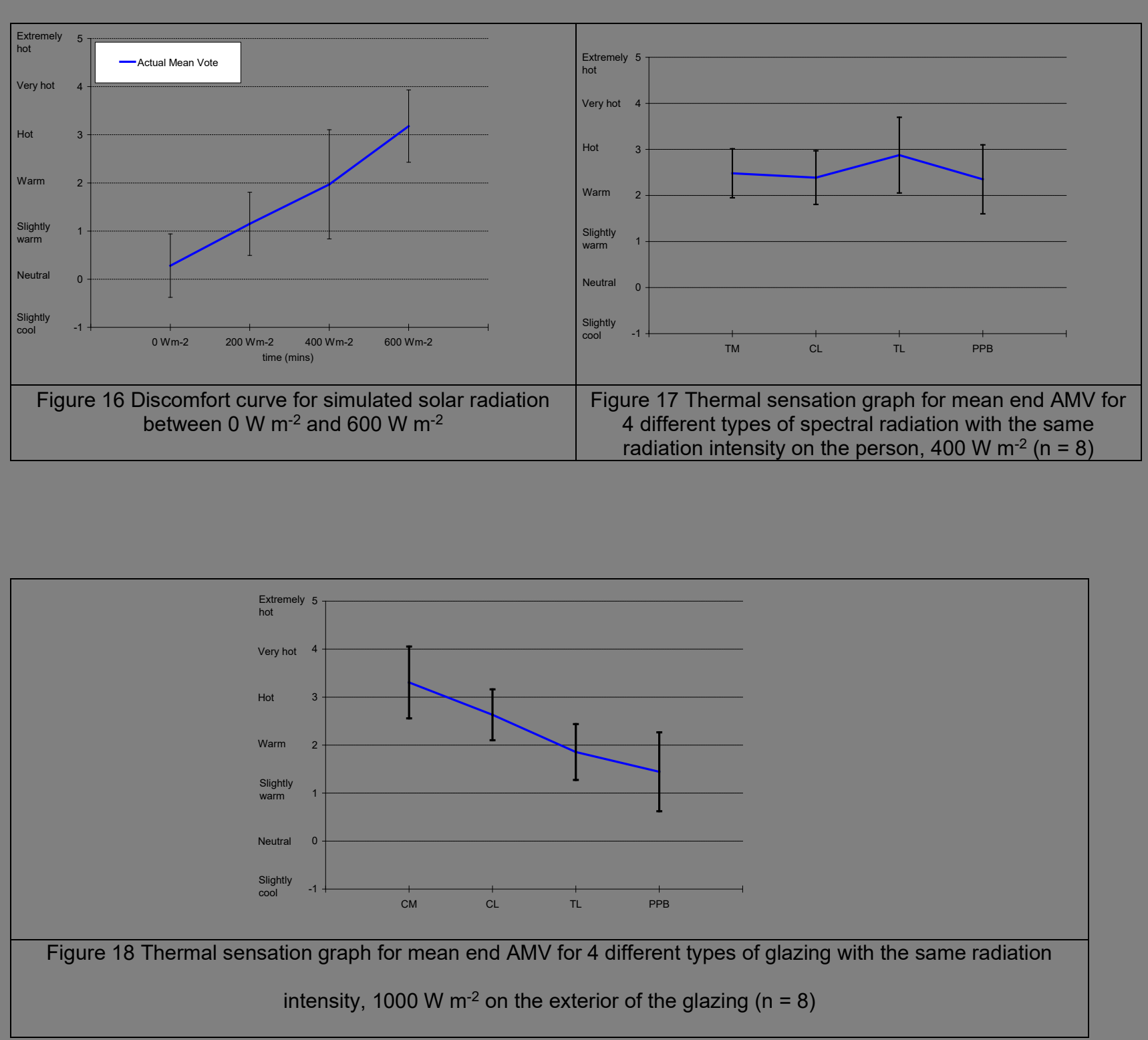
Table 1 Details of transmission, absorption and reflective qualities of the glazings (from Saint Gobain

Glazing, France)

\begin{tabular}{ccccccc}
\hline & \multicolumn{7}{c}{ Spectrophotometry } \\
Glazing type & TL \% & TE \% & RL \% & RE \% & AL \% & AE \% \\
\hline Tinted monolithic (TM) & 75 & 49 & 6 & 5 & 19 & 46 \\
Clear laminate (CL) & 89 & 79 & 7 & 7 & 4 & 14 \\
Tinted laminated (TL) & 76 & 50 & 7 & 5 & 17 & 45 \\
PPB clear glazing (PPB) & 77 & 50 & 9 & 25 & 14 & 25
\end{tabular}

$\mathrm{TL} \%$ is the percentage of the solar radiation transmitted in visible range $(380-760 \mathrm{~nm})$

TE $\%$ is the percentage of the solar radiation transmitted in total range of solar spectrum radiation

$\mathrm{RL} \%$ is the percentage of the solar radiation reflected in visible range $(380-760 \mathrm{~nm})$

$\mathrm{RE} \%$ is the percentage of the solar radiation reflected in total range of solar spectrum radiation

$\mathrm{AL} \%$ is the percentage of the solar radiation absorbed in visible range $(380-760 \mathrm{~nm})$

$\mathrm{AE} \%$ is the percentage of the solar radiation absorbed in total range of solar spectrum radiation

Table 2 Details of transmission, absorption and reflective qualities of the glazings

\begin{tabular}{ccccccc}
\hline & \multicolumn{7}{c}{ Spectrophotometry } \\
Glazing type & TL \% & TE \% & RL \% & RE \% & AL \% & AE \% \\
\hline Clear Monolithic (CM) & 90 & 84 & 8 & 8 & 2 & 8 \\
Clear Laminate (CL) & 89 & 79 & 7 & 7 & 4 & 14 \\
Tinted Laminated (TL) & 76 & 50 & 7 & 5 & 17 & 45 \\
PPB clear glazing (PPB) & 77 & 50 & 9 & 25 & 14 & 25 \\
\hline
\end{tabular}

Table 3 Summary of environmental data - study 1

\begin{tabular}{|c|c|c|c|c|}
\hline Simulated solar radiation & $600 \mathrm{~W} \mathrm{~m}^{-2}$ & $400 \mathrm{~W} \mathrm{~m}^{-2}$ & $200 \mathrm{~W} \mathrm{~m}^{-2}$ & $0 \mathrm{~W} \mathrm{~m}^{-2}$ \\
\hline ta shielded $\left({ }^{\circ} \mathrm{C}\right)$ & 24.0 & 23.4 & 23.4 & 22.8 \\
\hline $\operatorname{tr}\left({ }^{\circ} \mathrm{C}\right)$ derived from $\mathrm{tg}_{\mathrm{g}}$ & 44.0 & 41.8 & 37.7 & 24.2 \\
\hline Air Velocity $(\mathrm{m} / \mathrm{s})$ & 0.1 & 0.1 & 0.1 & 0.1 \\
\hline Relative Humidity (\%) & 49.6 & 51.0 & 51.4 & 48.3 \\
\hline PMV• & 0.2 & 0.1 & 0.1 & -0.1 \\
\hline PPD• & 6.8 & 8.8 & 7.1 & 6.2 \\
\hline $\mathrm{PMV} \dagger$ & 2.8 & 2.3 & 1.9 & 0.2 \\
\hline PPD† & 96.5 & 79.8 & 70.6 & 12.8 \\
\hline AMV & 3.1 & 1.9 & 1.1 & 0.2 \\
\hline APD & 100 & 75 & 62.5 & 12.5 \\
\hline
\end{tabular}


Table 4 Summary of environmental data Study 2

\begin{tabular}{crrrr}
\hline Glazing type & $\mathrm{CL}$ & \multicolumn{1}{c}{$\mathrm{TL}$} & \multicolumn{1}{c}{ PPB } & \multicolumn{1}{c}{$\mathrm{TM}$} \\
\hline $\mathrm{ta}_{\mathrm{a}}$ shielded $\left({ }^{\circ} \mathrm{C}\right)$ & 22.7 & 22.9 & 22.5 & 22.4 \\
$\mathrm{tr}_{\mathrm{r}}\left({ }^{\mathrm{C}}\right)$ derived from $\mathrm{tg}_{\mathrm{g}}$ & 39.5 & 35.0 & 34.2 & 34.8 \\
$\mathrm{t}_{\mathrm{g}}\left({ }^{\circ} \mathrm{C}\right)$ & 33.6 & 31.0 & 30.4 & 31.2 \\
Air Velocity $(\mathrm{m} / \mathrm{s})$ & 0.1 & 0.1 & 0.1 & 0.1 \\
Relative Humidity $(\%)$ & 49.9 & 48.8 & 51.9 & 48.3 \\
\hline PMV & 0.2 & 0.2 & 0.2 & 0.2 \\
$\mathrm{PPD} \cdot$ & 7.4 & 7.3 & 7.2 & 6.4 \\
$\mathrm{PMV} \dagger$ & 2.1 & 1.5 & 1.5 & 1.5 \\
$\mathrm{PPD} \dagger$ & 79.6 & 52.8 & 49.8 & 53.5 \\
$\mathrm{AMV}$ & 2.1 & 1.9 & 2.2 & 1.8 \\
$\mathrm{APD}$ & 79.4 & 71.1 & 87.0 & 68.6 \\
\hline
\end{tabular}

Table 5 Summary of environmental data at the position of the subjects (Note: $1000 \mathrm{~W} \mathrm{~m}^{-2}$ on the surface of the glazing)

\begin{tabular}{|c|c|c|c|c|}
\hline Glazing type & $\mathrm{CM}$ & $\mathrm{CL}$ & $\mathrm{TL}$ & PPB \\
\hline$t_{a}$ shielded $\left({ }^{\circ} \mathrm{C}\right)$ & 24.3 & 24.1 & 23.8 & 23.7 \\
\hline $\mathrm{t}_{\mathrm{r}}\left({ }^{\circ} \mathrm{C}\right)$ derived from $\mathrm{t}_{\mathrm{g}}$ & 37.5 & 36.2 & 31.0 & 31.1 \\
\hline Air Velocity $(\mathrm{m} / \mathrm{s})$ & 0.1 & 0.1 & 0.1 & 0.1 \\
\hline Relative Humidity (\%) & 31.6 & 33.8 & 37.2 & 32.2 \\
\hline Direct radiation $\left(\mathrm{Wm}^{-2}\right)$ & 628 & 577 & 339 & 308 \\
\hline PMV• & 0.1 & 0.1 & 0.0 & 0.0 \\
\hline PPD• & 5.1 & 5.2 & 5.0 & 5.0 \\
\hline $\mathrm{PMV} \dagger$ & 2.7 & 2.4 & 1.3 & 1.3 \\
\hline PPD† & 97.1 & 91.3 & 40.3 & 39.2 \\
\hline AMV & 3.3 & 2.6 & 1.8 & 1.4 \\
\hline APD & 100.0 & 98.0 & 84.2 & 68.0 \\
\hline
\end{tabular}

Table 6 Comparison of energy per sensation scale point for each condition

\begin{tabular}{ccccc}
\hline & $\mathrm{CL}$ & $\mathrm{CM}$ & $\mathrm{PPB}$ & $\mathrm{TL}$ \\
\hline AMV & 2.63 & 3.31 & 1.44 & 1.86 \\
$\begin{array}{c}\text { Energy per scale } \\
\text { point }\left(\mathrm{W} \mathrm{m}^{-2}\right)\end{array}$ & 219 & 189 & 165 & 182 \\
\hline
\end{tabular}

